\title{
LA GARANTÍA DEL FUNCIONAMIENTO DEMOCRÁTICO DE LOS PARTIDOS POLÍTICOS COSTARRICENSES
}

\section{COSTA RICAN POLITICAL PARTIES'S DEMOCRATIC PERFORMANCE GUARANTEE}

\author{
Mario A. Ramírez Granados*
}

RESUMEN

\begin{abstract}
El presente artículo analiza someramente el desarrollo de los partidos políticos y su funcionamiento interno en la legislación y la jurisprudencia electoral y constitucional costarricense, los alcances del principio democrático y sus manifestaciones en casos concretos.
\end{abstract}

PALABRAS CLAVE: COSTA RICA * PARTIDOS POLÍTICOS * DERECHO CONSTITUCIONAL * PARTICIPACIÓN POLÍTICA * DEMOCRACIA

\section{ABSTRACT}

The present article briefly analisis costarican political parties development and its internal functioning in the electoral and constitutional legislation and electoral jurisprudence, and the democratic principle, score and its manifestation in specific cases.

KEY WORDS: COSTA RICA * POLITICAL PARTIES * CONSTITUTIONAL LAW * POLITICAL PARTICIPATION * DEMOCRACY

Departamento legal, Asamblea Legislativa de Costa Rica.

maragra77@gmail.com 


\section{INTRODUCCIÓN}

GENERALIDADES: LOS PARTIDOS POLÍTICOS COMO ESPACIOS DE COMPETENCIA DEMOCRÁTICA

El concepto de partido político ha evolucionado desde la idea de las fracciones o grupos de interés de los siglos XVII y XVIII a nociones más amplias que los interpretan como instrumento para la competencia política. Se trata de organizaciones desde las que los diferentes grupos de la sociedad, compiten por el acceso al poder político en el cual visibilizan sus necesidades.

Los estudios sobre democracia generalmente analizan la competencia interpartidaria de un determinado grupo por el acceso al control de la dirección del Estado; dejando de lado la dimensión intrapartidaria, es decir, los conflictos entre las diferentes facciones al interior de un partido político.

Desde esta posición, surgen nuevos enfoques a nivel de las ciencias políticas que redefinen el concepto tradicional de partido político entendiéndolo como:

... un espacio de competencia objetivada entre agentes de tal modo dispuestos que luchen por la definición legítima del partido y por el derecho de hablar en nombre de la entidad y de la marca colectiva a la que ellos contribuyen, por su competencia, a conservar la existencia o más bien la creencia en su existencia (Offerlé, 2004: 37).

En un sentido similar, Alcántara Sáez indica que:

El liderazgo, plantea modelos de partidos que se localizan en un continuo, con un polo que cuenta con unos partidos con liderazgos que ven diluido su poder con otros, bien de carácter regional o pertenecientes a diferentes corrientes en el seno del partido, relaciones horizontales, amplio grado de democracia interna y de aquiescencia a las decisiones de la cúpula por parte de los militantes. Frente a ellos, en el polo opuesto, están los partidos con un liderazgo no diluido, monolítico y vertical, con poca democracia interna y un bajo nivel de comprensión y seguimiento de las medidas adoptadas por la cúpula por parte de los militantes (2004:181).

Esta definición amplia de partidos políticos conlleva a que se extienda la definición de los derechos políticos y el establecimiento de regulaciones que garanticen la competición política (Hernández Becerra, 2000) de todos los agentes al interior de una organización política.

La garantía de la competición política surge a partir de la constitucionalización de los partidos políticos como las principales organizaciones que obligan a que estos modifiquen sus regulaciones internas para garantizar el respeto a sus miembros. A esta regulación se le denominará, siguiendo a Hernández Valle, procesos de democratización interna.

De acuerdo con Hernández Valle, la democratización interna de los partidos es el conjunto de disposiciones normativas $y$ medidas políticas tendientes a garantizar:

a) La escogencia de los dirigentes internos.

b) La designación de las candidaturas a puestos de elección popular.

c) La determinación de la plataforma política; sean el resultado de la voluntad mayoritaria de los miembros del partido y no la imposición de las cúpulas políticas o económicas.

d) La financiación interna de los partidos políticos.

e) La representación proporcional por género.

f) La tutela de los derechos fundamentales de los miembros del partido mediante la existencia de un control heterónomo de constitucionalidad y legalidad sobre la actividad interna de los partidos políticos (2004:280-281).

El presente artículo pretende explorar la evolución de la competición política dentro de los partidos políticos costarricenses, la cual 
gira alrededor de dos conceptos centrales: el principio de autorregulación partidaria y la garantía constitucional de funcionamiento democrático. Esta última empieza a desarrollarse progresivamente a partir de la jurisprudencia de la Sala Constitucional, identificando nuevos contenidos y desarrollando los derechos políticos existentes.

\section{EL DEBATE SOBRE EL FUNCIONAMIENTO DEMOCRÁTICO DE LOS PARTIDOS POLÍTICOS EN COSTA RICA}

La regulación sobre partidos políticos en el Derecho Electoral Costarricense es tardía, debe entenderse que si bien el Tribunal Supremo de Elecciones surge como un medio para administrar los procesos de elecciones entre partidos políticos, a raíz de las acusaciones de fraude electoral que dieron lugar a la Guerra Civil de 1948; no existían normas expresas que obligaran a los partidos políticos a funcionar democráticamente, lo que permitió que los partidarios afectados no contaban con un medio efectivo para hacer valer sus derechos políticos.

Bajo esta óptica, los partidos políticos costarricenses gozan de libertad e independencia, cuentan con capacidad para brindarse su propio ordenamiento y organización interna mediante la figura de los Estatutos Partidarios.

Este ámbito de libertad incluye amplitud respecto a la formulación de sus declaraciones de principios y programas; libertad de organización interna y libertad respecto a los modos de designación de los candidatos a sus puestos de organización interna y los puestos de elección (Cf. García La Guardia, 2000: 259). Este ámbito de libertad es lo que en la doctrina electoral se conoce como el principio de autorregulación partidaria.

Esta situación vino a cambiar con la creación de la Sala Constitucional, que empieza a conocer de estos casos, bajo la figura del Recurso de Amparo. Indica en ese sentido, Castillo Víquez, la intervención de la Sala Constitucional se dio por:
La falta de remedios procesales efectivos en el Código Electoral para garantizar y proteger los derechos políticos de los ciudadanos, en especial en el seno de los partidos políticos, lo que provocó que en la práctica los ciudadanos acudieran a la Sala Constitucional a través del recurso de amparo (2008: 100-101).

Surgen entonces una serie de votos que delimitan la existencia de este principio dentro de las pautas de la interpretación constitucional, que garantizan el derecho fundamental a la participación política. Dentro de estos límites destaca el principio democrático.

El principio democrático se origina en una sentencia constitucional del año 1992, contra el adelantamiento de las asambleas distritales del Partido Liberación Nacional que no fue resuelto satisfactoriamente al interior de este partido político ni por el Tribunal Supremo de Elecciones, que declinó conocer el caso. Dicha sentencia indica que el derecho a la participación política puede ser defendido mediante la figura del Recurso de Amparo, indicando que no existe regulación sobre el control de los partidos políticos o sus órganos internos. Señala además, que los actos de los partidos políticos se encuentran en la competencia del Tribunal Supremo de Elecciones, pero que la Sala entra a conocerlos en los casos en que dicho Tribunal declina su competencia ${ }^{1}$.

La resolución de marras indica:

... no basta que el ciudadano se le permita la asociación a un partido político, sino que se requiere, a la par una verdadera posibilidad de participar internamente en ellos [...] El principio democrático que inspira nuestra organización política y social debe impregnar la actividad de los partidos políticos, que a pesar de la deficiente regulación con que cuentan, son entidades de derecho público (Sala Constitucional, resolución 2150-92

1 En ese entonces la normativa existente estipulaba la vigilancia de los partidos políticos a nivel nacional y provincial, dejando sin regulación las asambleas de tipo distrital y cantonal. 
de las doce horas del día ocho de agosto de 1992).

A partir de la resolución 2150-92, el derecho de participación política al interior de los partidos políticos se torna en un derecho exigible y el principio democrático se transforma en una garantía normativa ${ }^{2}$ producto del progresivo reconocimiento de la necesidad de que los partidos políticos funcionen de forma democrática.

Esto lleva a que la Asamblea Legislativa actualice el artículo 97 de la Constitución Política (que regula lo relativo a los partidos políticos) indicando que "su estructura interna y funcionamiento deberán ser democráticos".

La incidencia de la jurisprudencia constitucional sobre los partidos políticos, ante la falta de vigilancia del Tribunal Supremo de Elecciones cambia a partir del voto 303-E2000. En dicha resolución, el Tribunal Supremo de Elecciones reinterpreta el concepto de la vigilancia de los actos inherentes al sufragio para incorporar los actos de los partidos políticos, solucionando así el vacío normativo señalado por el Tribunal Constitucional en cuanto a la tutela de los derechos políticos por parte de los organismos electorales.

En dicha resolución, el Tribunal indica que con base en la jurisprudencia constitucional, el control de los actos partidarios corresponde a la esfera electoral. De modo que garantiza la vigilancia de las actuaciones de estas agrupaciones mediante la figura del Recurso de Amparo Electoral y la consulta de constitucionalidad, cuando los partidos por medio

$2 \quad$ Se entiende por garantía, la existencia de mecanismos encaminados a asegurar el cumplimiento de los derechos fundamentales y evitar su modificación mediante la legislación común o actos políticos (Cf. en ese sentido Pérez Luño, 2007: 66; Ferreyra, 2008: 131). De acuerdo con Ferreyra, se tratan de normas o reglas que van dirigidas a los poderes públicos, a fin de evitar que en el ejercicio de su actividad o su falta de ella (caso de inconstitucionalidad por omisión). A nivel de la legislación costarricense, Gutiérrez (1997) señalaba que si bien la Constitución de 1949 no utiliza expresamente esta figura, el concepto de garantía ha venido surgiendo a partir de la acción de la Sala Constitucional. de una norma estatutaria, restringen o no el derecho a la participación política. Este criterio se mantuvo en votos 3812-93 de las dieciséis horas con cuarenta y ocho minutos del seis de agosto de 1993 y 495-98 de las nueve horas con cuarenta y ocho minutos del veintinueve de enero de 1998.

Esto significa que el principio de funcionamiento democrático, garantiza el derecho de participación política en un status jurídico o de libertad dentro de un ámbito de condiciones mínimas, que garanticen su ejercicio pleno.

Finalmente, el artículo 97 de la Constitución Política se integra mediante la reforma al Código Electoral que introduce expresamente el control de las actividades partidarias por parte del Tribunal Supremo de Elecciones, la interpretación estatutaria mediante la consulta de constitucionalidad por parte del Comité Ejecutivo Partidario, la tutela de los derechos políticos mediante el Recurso de Amparo Electoral, el cual queda expresamente incorporado como un instrumento propio, entre otros.

\section{ALCANCES DEL FUNCIONAMIENTO DEMOCRÁTICO COMO GARANTÍA NORMATIVA}

A partir de la reforma constitucional y del cambio de orientación del Tribunal Supremo de Elecciones, se ha venido dando un desarrollo jurisprudencial de la garantía del funcionamiento democrático, que lo convierten en parámetro de control de los actos electorales $y$ principio informador en materia de interpretación e integración de las normas estatutarias al ordenamiento electoral. De la jurisprudencia del Tribunal Supremo de Elecciones, se desprenden tres funciones:

$\diamond \quad$ Como parámetro de desaplicación de normas estatutarias: Mediante el voto 393-E-2000 de las trece horas con quince minutos del quince de marzo de 2002, se establece que el Tribunal Supremo de Elecciones, en el ejercicio de su función de vigilancia de los actos electorales, puede revisar la constitucionalidad sobre normas estatutarias previamente 
inscritas, a través del Amparo Electoral. Esto sin perjuicio que dicha norma pueda ser impugnada directamente ante la Sala Constitucional.

$\diamond \quad$ Como parámetro de adecuación de actos electorales: Se establece como límite al principio de autorregulación partidaria, estableciéndose que los actos electorales sean generales o concretos de la órbita de la decisión o ejecución, deben ser analizados desde el principio democrático en el tanto el ejercicio del principio de autorregulación partidaria dificulte o imposibilite la participación de grupos o personas (ver voto 1440-E200; de las quince horas del catorce de julio de 2000; resolución 3507-E-2007 de las catorce horas con cincuenta $y$ dos minutos del veinte de diciembre de 2007).

$\diamond \quad$ Como principio de interpretación electoral: Desde el concepto constitucional de la interpretación del bloque de legalidad $y$ del principio de unidad del ordenamiento jurídico, se establece como principio general que frente a varias interpretaciones posibles de un precepto o de integración normativa ha de preferirse aquella que salve un potencial roce constitucional (Ver en ese sentido Tribunal Supremo de Elecciones. Resolución número 1724M-2003 de las doce horas del cinco de agosto de 2003). Por ejemplo, en el caso de una consulta del Partido Acción Ciudadana sobre la constitucionalidad de la norma estatutaria que limita el derecho a participar en la votación de asambleístas que eran aspirantes a una diputación, el Tribunal indicó que la norma debía interpretarse entendiendo que solo se inhibía a los aspirantes de participar de la metodología de votación, otra interpretación que restringiera su participación como asambleísta, afectaba su derecho a la participación política y estaba expresamente prohibida (Tribunal Supremo de Elecciones. Resolución 4251-
E-2008 a las catorce horas, cuarenta minutos del once de setiembre de 2009).

OTROS ALCANCES DE LA GARANTÍA DEL FUNCIONAMIENTO DEMOCRÁTICO

Además de estas reformas, dentro del Código Electoral, existen otras normas que tanto la Sala Constitucional como el Tribunal Supremo de Elecciones han incorporado. Entre ellas, manifestaciones del principio de funcionamiento democrático, como parte del bloque de legalidad, el cual explica y fundamenta el ejercicio del derecho a la participación política. Por ejemplo, el Tribunal Supremo de Elecciones, establece como condición de funcionamiento democrático la obligación de la renovación periódica de las estructuras partidarias, pues "no puede aceptarse las designaciones de carácter vitalicio o indefinido. Le corresponde a los Estatutos establecer plazos de elección que no superen el plazo máximo de cuatro años que marca el ciclo del periodo electoral" (Tribunal Supremo de Elecciones. Resolución 1536-E-2001 del veinticuatro de julio de 2001).

A nivel de la estructura de los partidos políticos nacionales, mediante la resolución 5379-97 de las catorce horas con treinta y seis minutos del cinco de setiembre de 1997, la Sala Constitucional eleva a rango constitucional el esquema de organización partidario por la normativa electoral como organización mínima necesaria para el cumplimiento del principio democrático ${ }^{3}$.

Esta norma establece como estructura mínima, la organización en asambleas distritales, cantonales, provinciales y nacional. Igualmente, indica que la designación de los miembros en cualquiera de estas asambleas debe respetar los principios democráticos y de

$3 \quad$ Cabe señalar que este criterio fue revisado recientemente en el voto 2010, que declara la inconstitucionalidad del artículo 61 del Código Electoral, que reproducía el orden distrito-cantón-país, proveniente del anterior Código Electoral. Sin embargo, debido a que el voto no ha sido publicado en su totalidad, impide analizar sus alcances en el presente estudio. 
representación (véase en ese mismo sentido Sala Constitucional. Voto 2881-99 de las quince horas con treinta $y$ tres minutos del seis de junio de 1999).

Sin embargo, recientemente, la Sala Constitucional resolvió una acción de inconstitucionalidad, en la que eliminó el nivel distrital, indicando que se convertía en un obstáculo para la inscripción de nuevos partidos políticos. Indica dicho voto:

Ciertamente, la celebración obligatoria de asambleas distritales es un requisito desproporcionado al obligar a la celebración de aproximadamente cuatrocientas sesenta $y$ cinco asambleas distritales, por lo que en cuanto a este punto, debe acogerse la inconstitucionalidad. No desconoce esta Sala que actualmente para poder inscribir un partido se debe realizar un proceso extenso y complejo consistente en la celebración de más de quinientas asambleas a lo largo $y$ ancho del país, por lo que, la declaratoria de inconstitucionalidad del inciso a) del artículo 60 del Código Electoral vigente implicaría que bastaría con celebrar 81 asambleas cantonales, 7 provinciales $y$ la nacional, exigencia que resulta más razonable y facilita el derecho constitucional de los ciudadanos de agruparse en partidos políticos (Sala Constitucional de la Corte Suprema de Justicia. Res. 2010009340. San José, a las catorce horas y treinta minutos del veintiséis de mayo de dos mil diez).

\section{MEDIOS DE DEFENSA JURISDICCIONALES}

Desde el voto 2150-92, el Recurso de Amparo se convirtió en el medio por excelencia para la defensa de los derechos políticos ante la falta de medios efectivos dentro del Código Electoral.

Posteriormente, el Tribunal Supremo de Elecciones mediante la resolución 303-E-2000, introduce el concepto de la figura del Amparo Electoral, que permite la revisión de los actos partidarios a la luz del principio democrático, entendido en forma amplia.

El Recurso de Amparo Electoral es un recurso sumario que permite salvaguardar la violación de los derechos políticos. Se encuentran legitimados para presentar dicha acción los afectados o las personas que ostenten al menos un interés legítimo. Al respecto, ha indicado el Tribunal Supremo de Elecciones mediante la resolución número 975 de las nueve horas del veintiocho de abril de 1999, sobre la legitimación en materia de derechos políticos:

Habrá de recordarse que sólo pueden intervenir en los procedimientos administrativos los titulares de un derecho subjetivo o interés legítimo que pueda resultar directamente afectado, lesionado o satisfecho, en virtud del acto final de tales procedimientos; $y$ el interés de la parte debe ser propio, legítimo y actual (art. 275 de la Ley General de la Administración Pública).

III. La legitimación, es decir, aquella aptitud para ser parte de un procedimiento administrativo, está entonces supeditada a tal condición, que también rige en el proceso contencioso-administrativo, el cual sólo puede ser incoado por las personas "que tuvieren interés legítimo y directo" en la eventual anulación de los actos cuestionados (art. 10.1.a de la Ley Reguladora de la Jurisdicción Contencioso-Administrativa). Por ello resulta de interés la exégesis contenida en la resolución nro. 134 de la Sala Primera de la Corte Suprema de Justicia, de las 14:35 horas del 23 de setiembre de 1992, la que sostiene que el interés de la parte actora... debe reunir algunas características para ser tutelable en sede administrativa $y$ jurisdiccional: en primer lugar, la anulación del acto debe suponer un beneficio para el demandante, el cual consiste en la eliminación de un acto perjudicial para él o, al menos, serle de utilidad o provecho. En segundo lugar, 
la repercusión de la anulación debe ser directa e inmediata sobre la situación jurídica del impugnante; por ende, el interés material debe ser transformado directamente por la anulación del acto impugnado. En tercer lugar, el interés debe ser personal, pues el beneficio de la anulación debe ser en favor del impugnante; de tal suerte, es necesaria una repercusión mediata o inmediata del acto administrativo en su esfera jurídica. Así, no es tutelable el denominado interés simple, a saber, aquel referente al respeto de la legalidad en la actividad de la administración, el cual puede corresponder a todos los ciudadanos o a grupos en particular, sin que se concrete en un sujeto determinado. En cuarto lugar, el interés debe ser actual y cierto; por ende, debe existir al momento de establecerse la demanda, ya sea porque se ha producido un daño o menoscabo, o porque éstos son previsibles en un futuro, conforme a las circunstancias normales del caso concreto. No son impugnables, de acuerdo con lo dicho, los daños simplemente hipotéticos o remotos. El perjuicio no necesariamente debe ser de índole patrimonial, pues podrían tutelarse intereses morales, siempre y cuando se trate de situaciones relevantes para el ordenamiento jurídico y su quebranto sea demostrado en el proceso.

Consecuentemente a pesar de la informalidad en la representación de los Recursos de Amparo Electoral, como instrumento para la defensa del derecho a la participación política; esto no exige al recurrente señalar cuáles son los hechos y los derechos subjetivos o intereses legítimos que resultan lesionados con los actos que cuestionan. Caso contrario, el Tribunal estaría asumiendo un control de legalidad en abstracto, desnaturalizando su función.

Con la reforma del Código Electoral, se regula expresamente el Amparo Electoral mediante los artículos 225 a 231 de este. Se establece como un medio para resguardar el derecho a la participación política de actos arbitrarios, acciones $\mathrm{u}$ omisiones fundados en normas erróneamente interpretadas o indebidamente aplicadas, actuaciones materiales. En estos casos, el causante de dicha conducta es un partido político o una persona en posición de poder que pueda afectar el ejercicio legítimo de los derechos fundamentales.

Sus requisitos de presentación están basados en la Ley de la Jurisdicción Constitucional, garantizando la informalidad y la gratuidad de dicho instrumento, sin que sea necesario el agotamiento de recursos al interior del partido político.

Respecto a la opinión consultiva sobre una norma jurídica por parte de los comités ejecutivos de los partidos políticos, prevista en el artículo 12 inciso e) del Código Electoral, no indica expresamente las formalidades que debe llevar.

\section{COROLARIO}

¿QUÉ QUEDA DEL PRINCIPIO DE AUTORREGULACIÓN PARTIDARIA?

A raíz de los alcances de la garantía del funcionamiento democrático, se concluye que en el Derecho Electoral Costarricense no existe una libertad de creación absoluta por parte de los partidos políticos, sino que los estatutos partidarios y las regulaciones partidarias deben crearse garantizando el ejercicio de participación política establecido constitucionalmente mediante el apego a los mínimos estatutarios establecidos dentro del Código Electoral. Existe un segundo nivel de protección, en el que el Tribunal revisa cuales normas o actos no dificultan o imposibilitan los derechos políticos, mediante el Recurso de Amparo Electoral del Tribunal Supremo de Elecciones.

Con el fin de entender los alcances del Principio de Autorregulación Partidaria, se procede a sistematizar diferentes casos a lo largo de diez años, desde que se da el cambio de criterio por parte del Tribunal Supremo de Elecciones.

Adelantamiento de procesos internos: los calendarios de procesos internos pueden 
ser modificados por las Asambleas Nacionales dentro del Principio de Autorregulación en el tanto no se restrinja irrazonablemente el derecho de los interesados en postularse. Por ejemplo, el Tribunal Supremo de Elecciones, mediante la resolución 3507-E-2007 de las catorce horas con cincuenta y dos minutos del veinte de diciembre de 2007, anuló las elecciones al puesto de Secretaría General del Partido Liberación Nacional, ya que restringía indebidamente el tiempo para hacer propaganda $y$ el darse a conocer de los aspirantes de dicho cargo.

Establecimientos de cuotas de inscripción: el Tribunal Supremo de Elecciones ha establecido que la imposición de una cuota para participar en procesos internos es una manifestación del Principio de Autorregulación partidaria establecido para financiar procesos internos dentro del esquema de financiación mixto previsto legalmente. Se indica que para ser razonable "debe ser un obstáculo infranqueable para la participación del candidato en el proceso electoral y que además dicho aporte tenga por objeto contribuir a la realización de proceso electorales internos de todos los aspirantes" (véase Tribunal Supremo de Elecciones. Resolución 303-E-2000 del quince de febrero de 2000 y Resolución 578-3-E-2001 de las once horas del veintitrés de febrero de 2001).

Puestos preferenciales: se trata de decisiones políticas de la Asamblea Nacional del Partido que pueden estar orientadas a garantizar la igualdad de oportunidades para grupos que hayan sido poco atendidos. Es el caso dentro del Partido Liberación Nacional, de los puestos para diputados para representantes de la Juventud y del Movimiento de Mujeres (véase en ese sentido Tribunal Supremo de Elecciones. Resolución 0578-3-E-2001 de las once horas del 23 de febrero de dos mil uno $)^{4}$.

Padrón abierto o Padrón cerrado: Para la Primera Convención del Partido Acción

$4 \quad$ En el caso de los representantes de Juventud, esta situación se modificó al establecerse en el artículo 52 del Código Electoral, que dentro del marco mínimo legal estatutario se debe garantizar asignarle a la juventud puestos en organización y de elección popular.
Ciudadana, una persona presentó amparo electoral alegando que dicho proceso electoral debía realizarse con padrón abierto y no con padrón cerrado, como lo había dispuesto la Asamblea Nacional del Partido Acción Ciudadana. En esa oportunidad, el Tribunal Supremo de Elecciones estableció que:

En cuanto a que el partido haya resuelto que se utilice un padrón cerrado para efectos de la convención que está por realizar, nótese que se trata de decisiones que responden al principio de autorregulación partidaria, por lo que tampoco se observan actuaciones que lesionen el derecho a la participación política del recurrente (Resolución 2449-E-2009 de las 13: 40 horas del 27 de mayo de 2009).

Ratificar y completar las nóminas para puestos de elección popular: De acuerdo con la jurisprudencia electoral, igualmente la Asamblea Nacional como órgano encargado de la dirección superior del Partido está facultada para nombrar los miembros faltantes cuando en un cantón no se haya podido cumplir con el proceso de elección, señala en ese sentido el Tribunal Supremo de Elecciones:

Si la Asamblea pese a la diligente labor desplegada por el partido tendiente a la celebración de una determinada asamblea, esta no llegare a celebrarse por razones imputables únicamente a su miembros, previa acreditación de 10 acontecido y autorización expresa del Registro Civil es posible avanzar y de esa manera celebrar la Asamblea Posterior (Resolución 1343-E-200 de las 14 horas del 30 de junio de 2000).

Con base en la jurisprudencia comentada anteriormente, se establece que las modalidades de la participación dentro de los procesos internos de los partidos políticos son fijados por el órgano encargado de la dirección política superior, esto es de conformidad con el ordenamiento electoral de la Asamblea Nacional de los 
partidos políticos, siempre y cuando se respeten los procesos electorales.

\section{CONCLUSIONES}

Los partidos políticos han ido evolucionando desde la concepción de entes cerrados a entes públicos, en espacios de lucha entre diferentes facciones o grupos políticos, liderazgos, entre otros, que compiten entre sí, por alcanzar la representación del partido para competir por el acceso al poder.

Esto ha llevado a que se especialice dentro del derecho público, el derecho electoral, como rama encargada de regular lo referente a la participación política. Dicha rama se conforma a partir de la constitucionalización de los partidos políticos, que garantiza el reconocimiento de dichas agrupaciones, su regulación interna y su financiamiento.

En el caso costarricense, los partidos políticos gozan de relevancia constitucional, al ser el espacio donde se ejerce la participación política. Su regulación es mínima, lo que permitía que en la práctica se dieran mecanismos de exclusión, bajo la regla de la autorregulación partidaria.

Esta situación cambia a partir de la Resolución 2150-92 de la Sala Constitucional que marcó un hito dentro del tema de la vigilancia de los partidos políticos, al volver exigible el derecho a la participación política, mediante la incorporación de la garantía de funcionamiento democrático, en un contexto de cambio en los liderazgos históricos de los principales partidos políticos.

La garantía de funcionamiento democrático de los partidos políticos se fortalecerá a partir de su inclusión en el artículo 97 de la Constitución Política y la jurisprudencia del Tribunal Supremo de Elecciones, que convierten al funcionamiento democrático en parámetro de los actos electorales, del principio general de interpretación electoral, del principio de desaplicación de normas estatuarias $y$ de otros aspectos de funcionamiento partidario. Como garantía jurisdiccional se incorpora como contenido de nombramientos de puestos partidarios, puestos de representación popular, equidad de género, entre otros.

A raíz de los alcances de la garantía del funcionamiento democrático se concluye que no existe una libertad de regulación absoluta por parte de los partidos políticos, sino que su funcionamiento se encuentra limitado a las normas electorales y a la jurisprudencia de la Sala Constitucional y del Tribunal Supremo de Elecciones, en aspectos como la participación mediante padrón abierto o cerrado, o la asignación de puesto o cuotas a la juventud, entre otras.

\section{BIBLIOGRAFÍA CONSULTADA}

\section{ARTÍCULOS DE REVISTA}

Brenes Villalobos, Luis Diego. "Protección de los derechos fundamentales en materia electoral por parte del Tribunal Supremo de Elecciones". Revista de Ciencias Jurídicas 101. Mayo-agosto, 2003.

Sobrado González, Luis Antonio. "La democratización interna de los partidos políticos en Costa Rica". Cuadernos de Ciencias Sociales 146. Abril. Flacso, 2007.

\section{DICCIONARIOS}

De la Peza, José Luis. "Interpretación de leyes electorales”. Fernández, Oscar; Rovira, Jorge (Editores académicos). Diccionario de Derecho Electoral. Tomo II. San José. Instituto de Derechos Humanos (IIDH). 2003:718-730.

García La Guardia, Jorge Mario. "Constitucionalización de los partidos políticos". Fernández, Oscar; Rovira, Jorge (Editores académicos). Diccionario de Derecho Electoral. Tomo I. San José. Instituto de Derechos Humanos. 2000: 254-262.

Hernández Becerra, Augusto. "Competitividad". Fernández, Oscar; Rovira, Jorge (Editores académicos). Diccionario de Derecho Electoral. Tomo I. San José. 
Instituto de Derechos Humanos. 2000: 219-222.

Orozco Henríquez, J. Jesús y Silva Araya, Carlos. "Medios de impugnación". Fernández, Oscar; Rovira, Jorge (Editores académicos). Diccionario de Derecho Electoral. Tomo II. San José. Instituto de Derechos Humanos. 2003: 844-845.

\section{JURISPRUDENCIA CONSTITUCIONAL}

Sala Constitucional. Resolución 2150-92 de las 12 horas del día 8 de agosto de 1992.

Sala Constitucional. Voto 3812-93 de las 16 horas con 48 minutos del 6 de agosto de 1993.

Sala Constitucional. Voto $5379-97$ de las 14 horas con 36 minutos del 5 de setiembre de 1997.

Sala Constitucional. Voto 495-98 de las 9 horas con 48 minutos del 29 de enero de 1998.

Sala Constitucional. Voto 2881-99 de las 15 horas con 33 minutos del 6 de junio de 1999.

\section{JURISPRUDENCIA ELECTORAL}

Tribunal Supremo de Elecciones. Resolución 907 de las 11 horas con 30 minutos del 18 de agosto de 1997.

Tribunal Supremo de Elecciones. Resolución 975 de las 9 horas del 28 de abril de 1999.

Tribunal Supremo de Elecciones. Resolución 303-E-2000 del 15 de febrero de 2000.

Tribunal Supremo de Elecciones. Resolución $393-\mathrm{E}-2000$ de las 13 horas con 15 minutos del 15 de marzo de 2002.

Tribunal Supremo de Elecciones. Resolución $1343-\mathrm{E}-2000$ de las 14 horas de 30 de junio de 2000.

Tribunal Supremo de Elecciones. Resolución 1440 -E-2000 de las 15 horas del 14 de julio de 2000.

Tribunal Supremo de Elecciones. Resolución 0578-3-E-2001 de las 11 horas del 23 de febrero de 2001.

Tribunal Supremo de Elecciones. Resolución 1536-E-2001 del 24 de julio de 2001.
Tribunal Supremo de Elecciones. Resolución número 1724-M-2003 de las 12 horas del 5 de agosto de 2003.

Tribunal Supremo de Elecciones. Resolución $3507-E-2007$ de las 14 horas con 52 minutos del 20 de diciembre de 2007.

Tribunal Supremo de Elecciones. Resolución 4251-E-2008 de las 14 horas 40 minutos del 11 de setiembre de 2009 .

Tribunal Supremo de Elecciones. Resolución 2449-E-2009 de las 13 horas con 40 minutos del 27 de mayo de 2009.

\section{LEGISLACIÓN}

Asamblea Legislativa. Código Electoral. Ley 8765 del 19 de agosto de 2009.

LIBROS

Alcántara Sáez, Manuel. Instituciones o máquinas ideológicas: origen, programa y organización de los partidos latinoamericanos. España. Instituto de Investigaciones Políticas y Sociales. Universidad de Barcelona, 2004.

Araya Pochet, Carlos. "Partidos políticos, derecho constitucional y reforma electoral: balance y perspectivas 19862000". Rovira Mas, Jorge (editor). La democracia de Costa Rica en el siglo XXI. Editorial Universidad de Costa Rica, 2001.

Castillo Víquez, Fernando. La protección de los derechos fundamentales en la jurisdicción constitucional y sus vicisitudes. San José: Editorial Juritexto, 2008.

Ferreyra, Raúl Gustavo. Notas sobre Derecho Constitucional y garantías. Buenos Aires: EDIAR Sociedad Anónima Editora, 2008.

Gutiérrez Gutiérrez, Carlos José. "Garantías de los Derechos fundamentales". Bertolini, Anarella; Fernández, Hubert (editores). La jurisprudencia constitucional y su influencia en el Estado de Derecho. San José: EUNED, 1996. 
Hernández Valle, Rubén. Derecho Electoral Costarricense. San José: Editorial Juricentro, 2004.

Hernández Valle, Rubén. "Regulación jurídica de los partidos políticos en Costa Rica". Zovatto, Daniel (coord.). Regulación jurídica de los partidos politicos en América Latina. México: UnAm/ International IDEA, 2006.
Offerlé, Michel. Los partidos políticos. Santiago, Chile: Ediciones LOM. 2004.

Pérez Luño, Antonio E. Los derechos fundamentales. Novena Edición. Madrid: Editorial Tecnos, 2007.

Fecha de ingreso: $07 / 12 / 2010$ Fecha de aprobación: 25/04/2011 
